\title{
Effect of MnS Inclusions Distribution on Intragranular Ferrite Formation in Medium Carbon Non-Quenched and Tempered Steel for Large-Sized Crankshaft
}

\author{
Jinlong LU, Yunpeng WANG, Qiming WANG, Huijing CHENG and Guoguang CHENG* \\ State Key Laboratory of Advanced Metallurgy, University of Science and Technology Beijing, 30 Xueyuan Road, Haidian \\ District, Beijing, 100083 P. R. China.
}

(Received on July 17, 2018; accepted on November 13, 2018; J-STAGE Advance published date:

December 20, 2018)

\begin{abstract}
A novel quantitative characterization method of $\mathrm{MnS}$ distribution was proposed based on the data from automatic inclusions analysis software to evaluate their effects on intragranular polygonal ferrite (IPF) formation in medium carbon non-quenched and tempered steels. The results show that agminated $\mathrm{MnS}$ inclusions in the steel are less effective to promote the IPF formation and lots of inclusions are actually wasteful because their space distances are too small to act as nucleation sites individually, even their number is larger than that in the steel with plentiful uniformly distributed MnS inclusions. Due to the difference of observation method, three-dimensional dendritic MnS inclusions would be revealed as several agminated small-sized ones in two-dimensional observation. In order to avoid misunderstanding, the characteristics of the nearest space distances between inclusions in widely used two-dimensional observation could be applied to recognize and define these agminated MnS inclusions to more accurately evaluate their effects on IPF formation.
\end{abstract}

KEY WORDS: non-quenched and tempered steel; MnS; distribution; intragranular polygonal ferrite; nearest space distance; crankshaft.

\section{Introduction}

Medium carbon non-quenched and tempered (NQT) steels are widely applied to manufacture the automotive parts such as crankshafts and connecting rods, for their low cost, high metal yield and simple production process. ${ }^{1-3)}$ The micro-alloying and thermo mechanical control process technologies have been used to improve mechanical properties of NQT steels with precipitation strengthening or microstructure refinement. However, for NQT steels used for hot forged crankshafts of heavy trucks, their sizes are large and austenitizing temperature would be as high as $1200^{\circ} \mathrm{C}$. Moreover, the austenite deformation during hot die forging process is insufficient and the cooling rate after forging is slow for fear of non-uniform properties on large cross section. As a result, the final microstructures of large-sized crankshafts are usually coarse pearlite and grain boundary ferrite (GBF), resulting in poor mechanical performance., ${ }^{4,5)}$

In recent years, intragranular polygonal ferrite (IPF) induced by non-metallic inclusions has been applied to refine the microstructures of ferrite-pearlite steels. ${ }^{6-14)}$ In NQT steel, the primary nucleating agents are $\mathrm{MnS}+\mathrm{V}(\mathrm{C}$, $\mathrm{N})$ particles, which possess Baker-Nutting orientation relationship with $\alpha$-Fe and need low energy to form the

\footnotetext{
* Corresponding author: E-mail: chengguoguang@metall.ustb.edu.cn DOI: https://doi.org/10.2355/isijinternational.ISIJINT-2018-509
}

new interface. ${ }^{11-13)}$ Hence, it is significant to investigate the effects of MnS inclusions on IPF formation in order to generate more efficient nucleation sites before the final forging process.

Zhao et al. ${ }^{9)}$ studied the influence of MnS size on their nucleation ability for IPF and found with the increase of the size, their nucleation ability decreased rapidly, so the tiny inclusions were more desired. Furuhara et al. ${ }^{12)}$ found the nucleation potency of single $\mathrm{MnS}$ inclusion would increase with its size increasing because more $\mathrm{V}(\mathrm{C}, \mathrm{N})$ particles would generate on it. For the numbers of $\mathrm{MnS}$ inclusions, more is better as long as their influences on the steel performance are acceptable. However, the distribution characteristics of $\mathrm{MnS}$ have received limited attention even they are also critical to the IPF formation. For example, IPFs only generate on the $\mathrm{MnS}+\mathrm{V}(\mathrm{C}, \mathrm{N})$ particles located inside of the prior austenite, if the $\mathrm{MnS}+\mathrm{V}(\mathrm{C}, \mathrm{N})$ particles are distributed along the boundary of the prior austenite, they would promote GBF formation instead. ${ }^{16)}$

Furthermore, in our previous study, ${ }^{17)}$ it was found that there was huge difference between two-dimensional (2D) and three-dimensional (3D) morphologies of type II MnS inclusions, as shown in Fig. 1. In 2D observation, MnS inclusions are small in size, large in number and discrete in distribution. But after corroded, they are large size and show dendritic shape. It can be inferred that the MnS inclusions of 2D observation are actually the secondary dendrites 


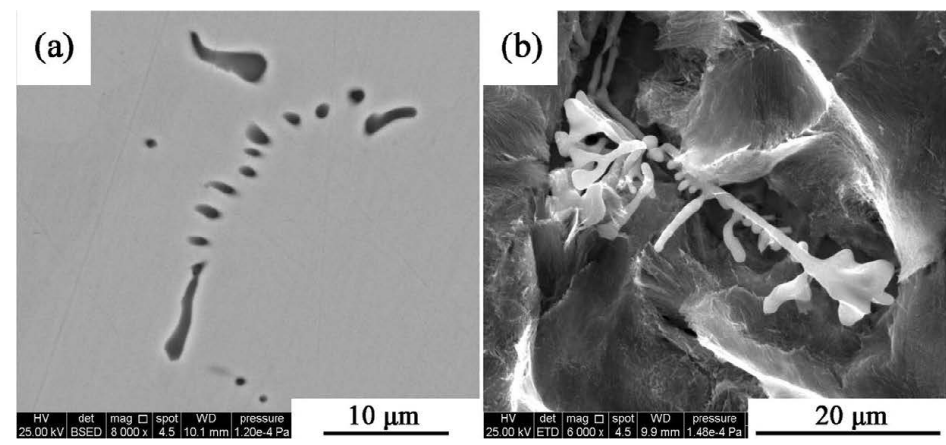

(c)

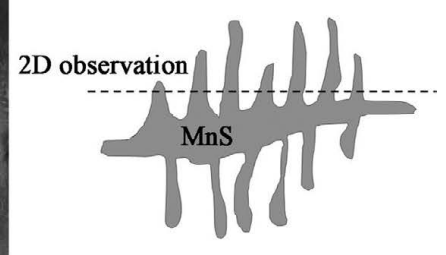

Fig. 1. Morphologies of $\mathrm{MnS}$ inclusions, (a) is 2D observation, (b) is 3D observation and (c) is schematic diagram of difference between 2D and 3D observation. ${ }^{17)}$

of the real $\mathrm{MnS}$ inclusions. The similar results were also reported in other dendritic or clustered inclusions, such as $\mathrm{Al}_{2} \mathrm{O}_{3}$ oxides. ${ }^{18,19)}$ That means the quantifications of number and size of $\mathrm{MnS}$ inclusions in 2D observation are imprecise sometimes, and so is their influence on the IPF formation. Therefore, it is more meaningful and necessary to investigate the distribution characteristics of $\mathrm{MnS}$ inclusions to evaluate their influence on the IPF formation. MnS inclusions are usually classified as evenly distributed and agminated, but how to judge it or the quantification method was hardly reported in previous studies.

With the development of the electronic scanning technology, automatic inclusions analysis systems, such as Aspex $^{20,21)}$ and INCA Explorer, ${ }^{8,17)}$ are widely applied in steel material research. It can not only obtain abundant size and number characteristics of inclusions within a short time, but the relative position information is also recorded simultaneously, which means this position information can be analyzed to quantify the inclusions distribution characteristics.

So, in this paper, a novel method was proposed to quantify the distribution characteristics of $\mathrm{MnS}$ inclusions based on the data obtained from the INCA system. The effect of $\mathrm{MnS}$ distributions, especially the agminated ones on the IPF formation was discussed according to the quantitative results.

\section{Experimental Procedure}

\subsection{Sample Preparation and Observation}

Two ingots were prepared in laboratory and the detailed smelting process was reported in previous paper. ${ }^{17)}$ Then, the ingots were homogenized at $1200^{\circ} \mathrm{C}$ for 2 hours, subsequently forged into bars with diameter of $40 \mathrm{~mm}$ and cooled in air to the ambient temperature. A BS2400u non-contact infrared thermometer was applied to measure the cooling rate and the value was $0.3-1.0 \mathrm{~K} \cdot \mathrm{s}^{-1}$.

The chemical compositions of the as-forged bars are shown in Table 1. S1 is the sample steel with lower $\mathrm{Zr}$ content and its contents of $\mathrm{Al}$ and $\mathrm{O}$ are higher. S2 is $\mathrm{Zr}$ killed steel and the contents of $\mathrm{Al}$ and $\mathrm{O}$ are lower. The other elements, such as C, Si, Mn, P, S, V and N are similar in two sample steels.

Metallographic samples with size of $12 \times 12 \times 7 \mathrm{~mm}^{3}$ were machined from the as-forged bars. After ground and polished, they were detected with a FEI Quanta MLA250 scanning electron microscope (SEM) to observe the inclusions
Table 1. Chemical compositions of the sample steels (mass $\%$ ).

\begin{tabular}{ccccccccccc}
\hline Steel & $\mathrm{C}$ & $\mathrm{Si}$ & $\mathrm{Mn}$ & $\mathrm{P}$ & $\mathrm{S}$ & $\mathrm{V}$ & $\mathrm{Al}$ & $\mathrm{Zr}$ & $\mathrm{O}$ & $\mathrm{N}$ \\
\hline $\mathrm{S} 1$ & 0.37 & 0.60 & 1.45 & 0.0083 & 0.043 & 0.13 & 0.0052 & 0.0010 & 0.0062 & 0.01 \\
$\mathrm{~S} 2$ & 0.37 & 0.58 & 1.48 & 0.0075 & 0.054 & 0.12 & 0.0028 & 0.0066 & 0.0032 & 0.0098
\end{tabular}

(a)

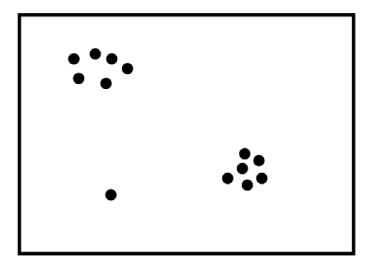

(b)

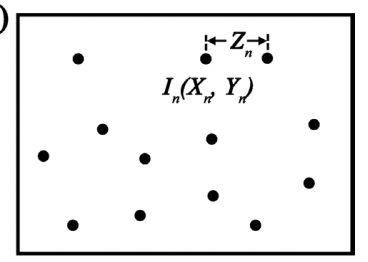

Fig. 2. Schematic diagrams of two different distributions of inclusions, (a) is agminated and (b) is relatively uniform. $X n$ and $Y n$ are the horizontal ordinate and vertical coordinate of one inclusion (In), respectively, $Z n$ is the nearest space distance between $I n$ and the other inclusions.

morphology. The chemical compositions of the inclusions were analyzed by energy dispersive X-ray spectrometer (EDS) connected to the SEM. In order to study the microstructures of two sample steels, some metallographic samples were etched by 3 volume $\%$ nital solution and followed by observation with Leica DM4M optical microscope (OM) and SEM-EDS. The different microstructure characteristics were measured with a manual point counting procedure. A grid superimposed on microstructure micrographs, counting the number of placements in different microstructures. An unbiased statistical estimation could be obtained.

The relative position information of $\mathrm{MnS}$ inclusions was obtained by the INCA system connected to the EVO18 SEM-EDS. The scanning area of each metallographic sample is about $10 \mathrm{~mm}^{2}$ and the minimum width of inclusions detectable is set as $0.5 \mu \mathrm{m}$ in consideration that $\mathrm{MnS}$ inclusions were lengthened during the forging process. The method to quantify the distribution characteristics of $\mathrm{MnS}$ inclusions is described in detail below.

\subsection{Quantitative Method}

The horizontal ordinate, named as $X n$ and vertical coordinate, named as $Y n$ of each inclusion could be obtained with the INCA system. If the total number of inclusions is $N$, then, the space distances between one inclusion (In) and the other $N-1$ inclusions could be calculated with Matlab software and the nearest one, defined as $Z n$, could be selected. If inclusions are agminated in distribution, as shown in Fig. 2(a), the most values of $Z n$ are quite small. As a contrast, the 
values of $Z n$ in Fig. 2(b) are larger because the inclusions are relatively uniform and separate in distribution. A critical value could be defined to determine the distribution of inclusions quantitatively. If the $Z n$ of inclusions is larger than the critical value, they are identified as equally distributed, otherwise they are regarded as agminated. In this paper, the critical value is the equivalent circle diameter (ECD) of IPF.

\section{Results and Discussion}

\subsection{Microstructures}

The air-cooled microstructures of two sample steels after forging are shown in Fig. 3. Both steels consist of white network-like GBF, white IPF and gray pearlite (P) structures. GBF structures in $\mathrm{S} 1$ are more obvious and they are continuous along the boundary of prior austenite grains. Due to the high austenitizing temperature and long holding time, the sizes of most prior austenite grains are about 100 $\mu \mathrm{m}$. The GBF structures in S2 are not distinct because more IPF structures are generated inside of the network-like GBF, resulting in much more refined microstructures.

The volume fractions of IPF, GBF and P structures are shown in Fig. 4. In S2, the amount of desired IPF structures is as high as $15.3 \%$ while the value in $\mathrm{S} 1$ is only $4.2 \%$. Besides, the volume fraction of $\mathrm{P}$ is nearly $10 \%$ smaller than that in S1. It is generally recognized that the content of main alloying elements, namely $\mathrm{C}, \mathrm{Si}, \mathrm{Mn}, \mathrm{V}$ and $\mathrm{N}$, the cooling rate after forging and the heterogeneous nuclei are three main factors that influence austenite to $\alpha$-ferrite phase transformation and the volume fractions of different microstructures. ${ }^{9)}$ However, the first two factors stated above are almost the same in present study. Hence, inclusions in the steel formed by $\mathrm{Zr}, \mathrm{O}, \mathrm{S}$ and $\mathrm{Mn}$ elements, ${ }^{17)}$ which have been proved to be quite effective as heterogeneous nuclei to promote proeutectoid ferrite, ${ }^{7,8,11-13)}$ are regarded as the main causes of different microstructures in two sample steels.

\subsection{IPF Characterizations}

The SEM morphologies of IPF structures in two sample steels are shown in Fig. 5. The polygonal gray structures are ferrites, the light white structures are $\mathrm{P}$ and the white points inside of IPFs are $\mathrm{MnS}$ inclusions, which are shown in Fig. 6. It should be mentioned that some $\mathrm{V}(\mathrm{C}, \mathrm{N})$ particles, which are too small to be detected with SEM, have been verified at the edge of $\mathrm{MnS}$ inclusions in our previous research. ${ }^{8)}$ Because $\mathrm{V}(\mathrm{C}, \mathrm{N})$ particles are not the focus of the present study, the nucleation sites of IPF are unified as $\mathrm{MnS}$ inclusions for simplicity.

From the Fig. 5, many MnS inclusions inside of IPFs in $\mathrm{S} 1$ are agminated and show chain and cluster shape. But in $\mathrm{S} 2$, there is only one or two white point-like MnS inclusions within the most IPF structures. The volume fraction of IPF is usually proportional to the number of inclusions inside of the prior austenite grains in view that each inclusion possesses the nucleation ability. However, in S1, the $\mathrm{MnS}$ inclusions are clustered in local part, leading to several

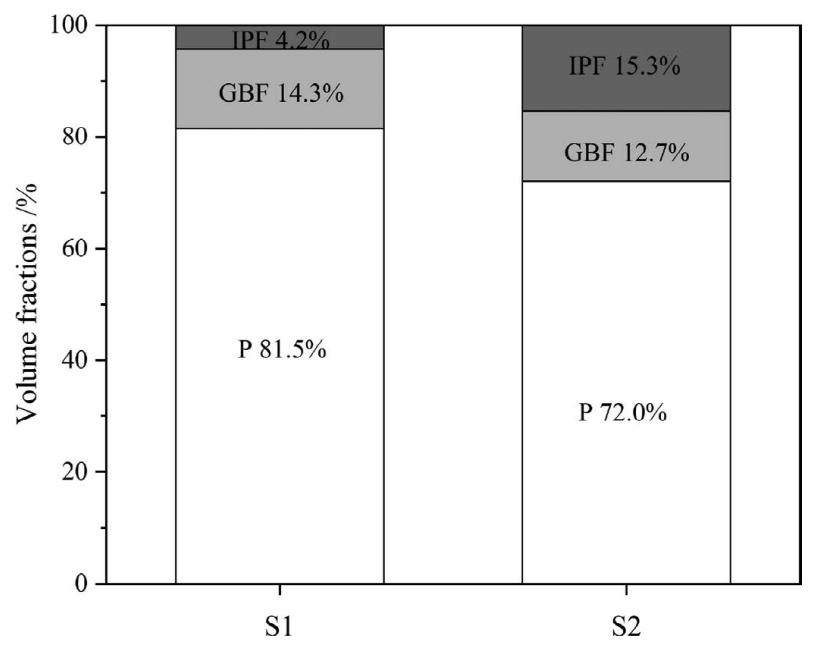

Fig. 4. Volume fractions of different microstructures in two sample steels.

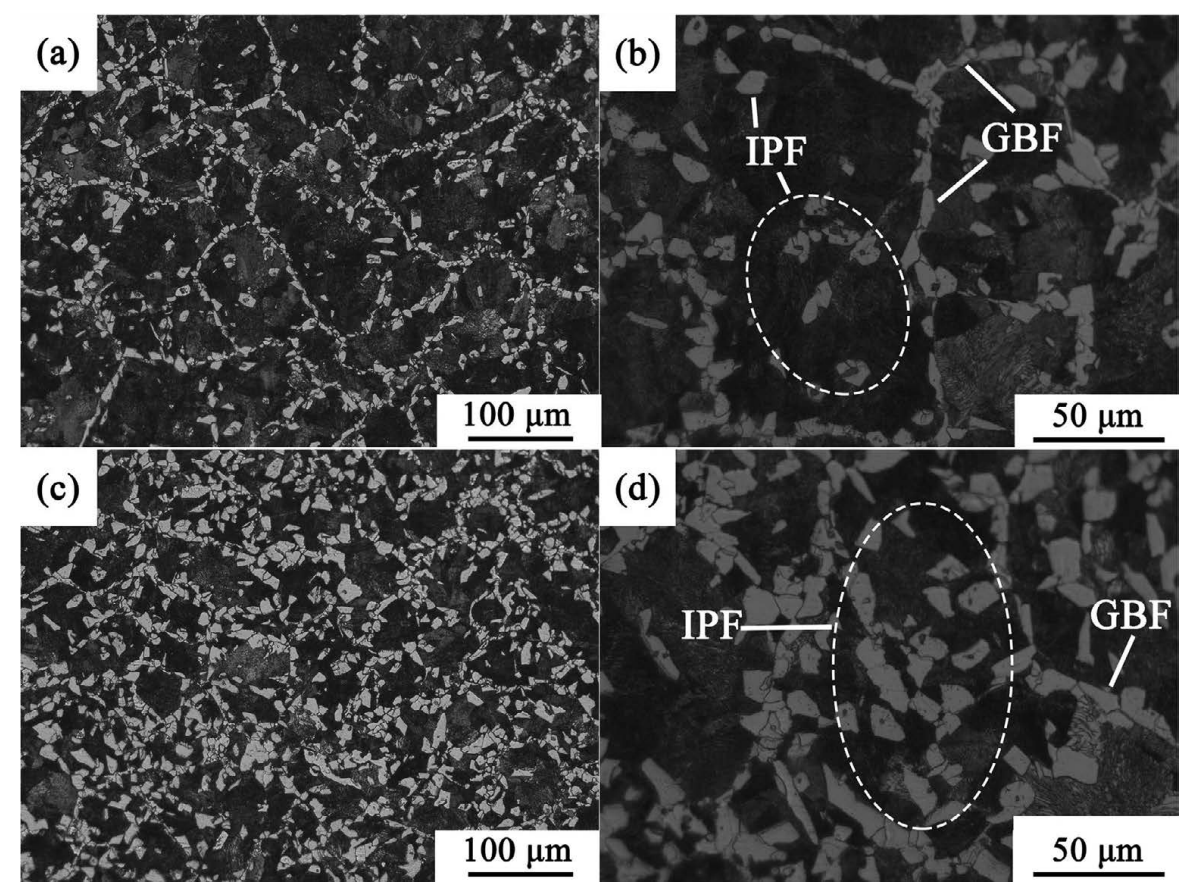

Fig. 3. Microstructures of two sample steels, (a, b) S1 and (c, d) S2. 

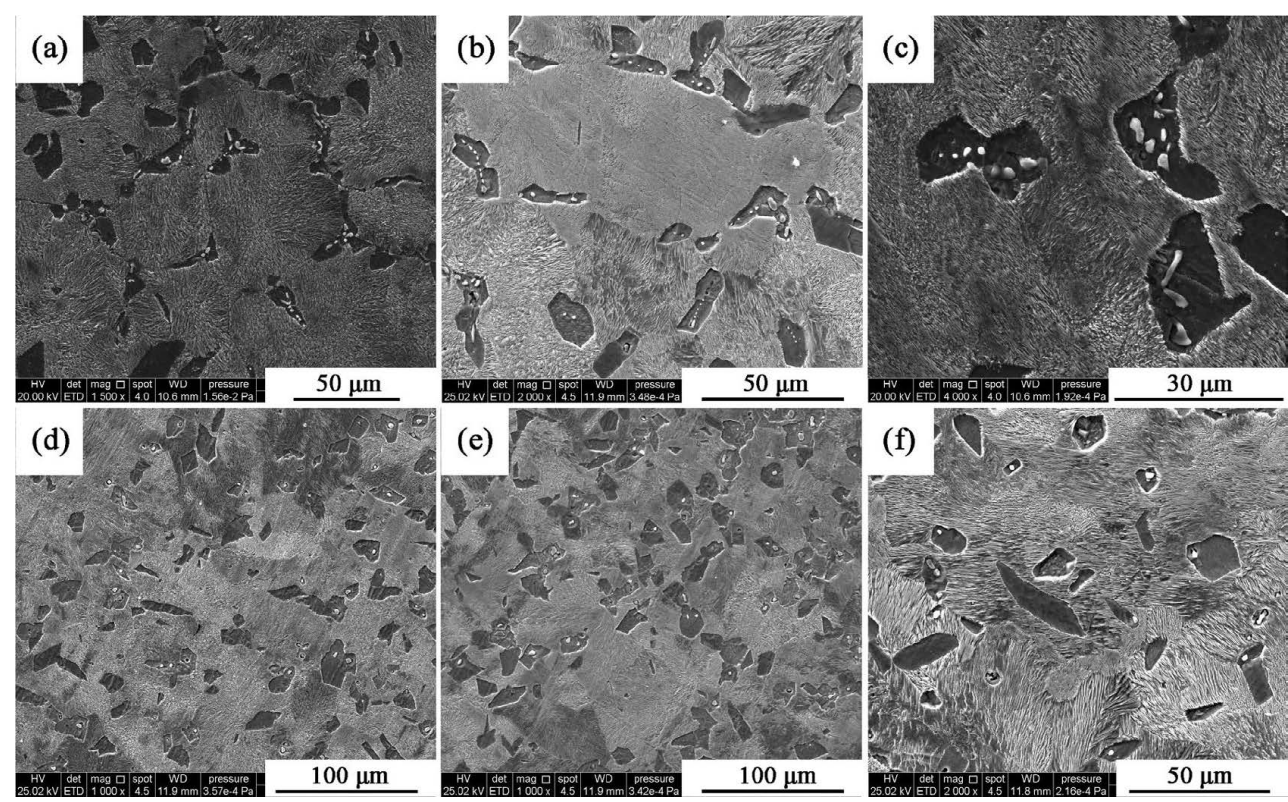

Fig. 5. SEM morphologies of microstructures in two sample steels, (a-c) S1 and (d-f) S2.
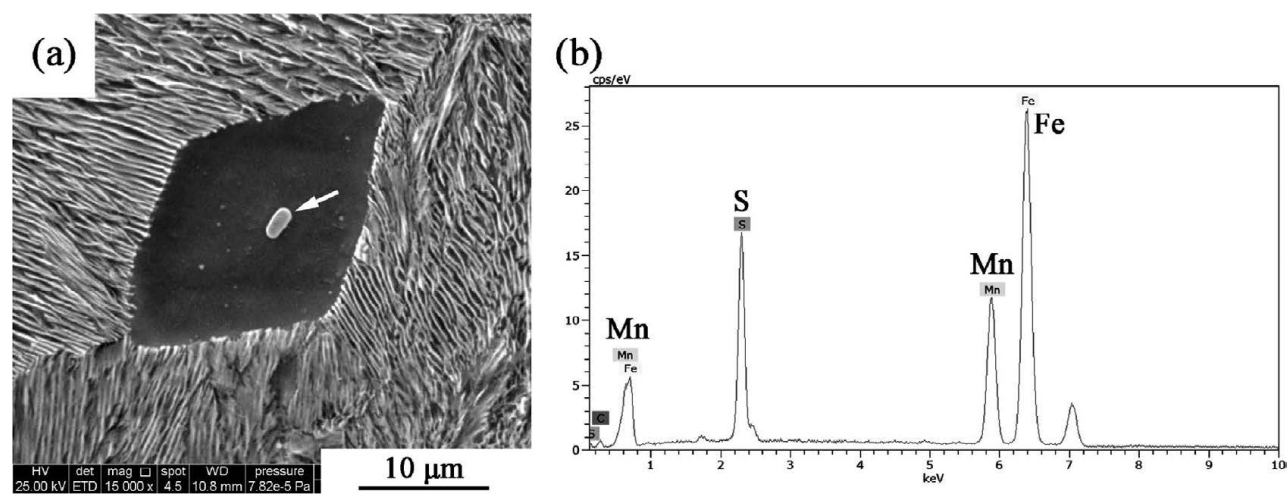

Fig. 6. SEM morphology of IPF grain and EDS spectrum of MnS inclusion.
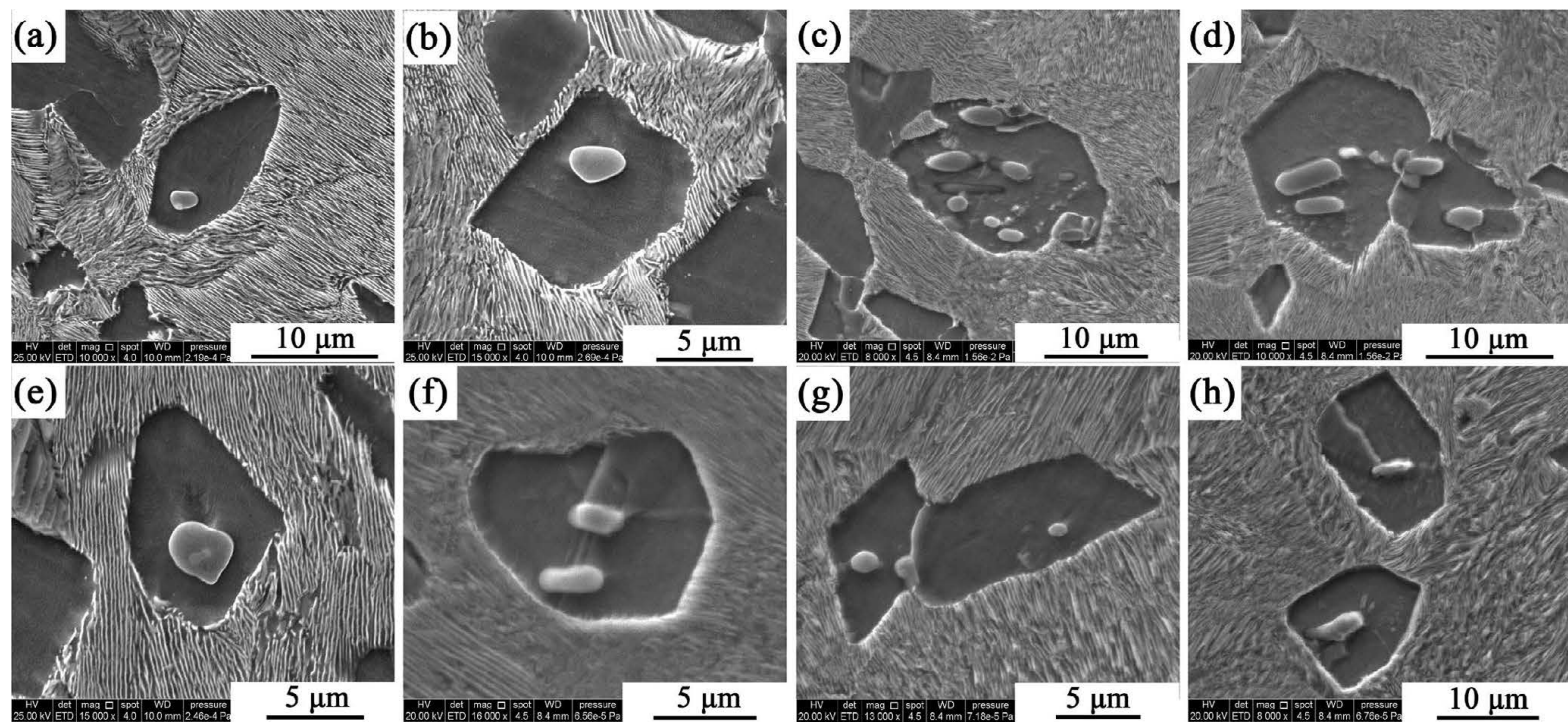

Fig. 7. SEM morphologies of MnS and IPF in two sample steels, (a-d) S1 and (e-h) S2

MnS inclusions promoting only one IPF structure. In other words, these agminated $\mathrm{MnS}$ inclusions have only provided one nucleation site and most inclusions are wasteful in fact. However, in S2, the MnS inclusions are more equally distributed and adequately utilized.
The individual IPF structures under high magnification with SEM are shown in Fig. 7. It is obvious that one MnS inclusion is sufficient to induce the IPF structures, as shown in Figs. 7(a), 7(b) and 7(e). If space distance of two MnS inclusions is tiny, as shown in Fig. 7(f), they would promote 
only one IPF structure. With the increase of space distance between two inclusions, they would induce IPF nucleation individually. But with the growing up of IPF, they would contact and combine, as shown in Fig. 7(g). Only if the space distance between two inclusions is far enough, there would be two IPFs generated, just like Fig. 7(h). In S1, a lot of $\mathrm{MnS}$ inclusions are located very close to each other, as shown in Figs. 7(c) and 7(d), only one IPF structure is formed.

100 IPF structures are randomly selected in two sample steels to count the number of MnS inclusions inside. The result is shown in Fig. 8. In $\mathrm{S} 1$, there are $548 \mathrm{MnS}$ inclusions inside of the 100 selected IPF structures, which means 5.48 MnS inclusions serve as one effective nucleation site to induce IPF averagely in S1. In S2, the value is only 1.21 because $\mathrm{MnS}$ inclusions are much more evenly distributed. That indicates the nucleation availability of $\mathrm{MnS}$ inclusions is greatly affected by their distribution characteristics.

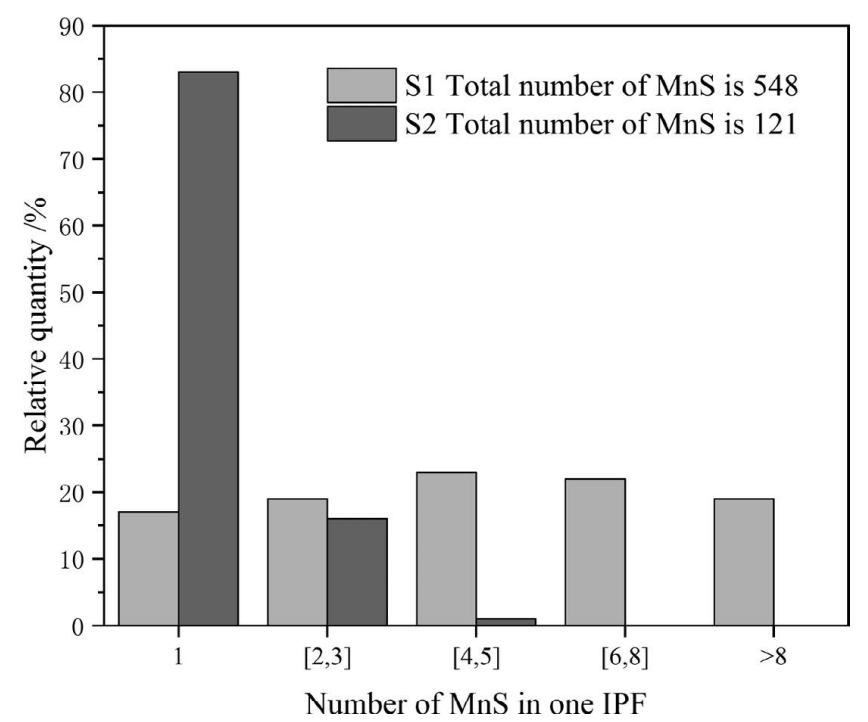

Fig. 8. Relative quantity against $\mathrm{MnS}$ number inside single IPF in two sample steels.

\subsection{MnS Characterizations}

3.3.1. Morphology, Amount and Size

The SEM morphologies of MnS inclusions in transverse section of as-forged bars are shown in Fig. 9. Most MnS inclusions are point-like and some are short rod-like in both sample steels. It is obvious that $\mathrm{MnS}$ inclusions in $\mathrm{S} 1$ are more agminated than those in S2. Besides, MnS inclusions in $\mathrm{S} 1$ seem smaller in size and larger in number than those in S2. Figures 9(d) and 9(h) are reproduced MnS morphologies based on the data from Figs. 9(c) and 9(g). Compared with the corresponding SEM morphologies, MnS inclusion characteristics are precisely the same, indicating that INCA data is credible. It should be noted that $\mathrm{MnS}$ inclusions in present paper mean all sulfides, including pure MnS inclusions and oxide-sulfide duplex inclusions.

The accurate statistical result of $\mathrm{MnS}$ inclusions amount and size based on INCA system is revealed in Fig. 10. The $\mathrm{MnS}$ inclusions number in $\mathrm{S} 1$ is $768.3 / \mathrm{mm}^{2}$ while the value in $\mathrm{S} 2$ is $466.4 / \mathrm{mm}^{2}$ and the average sizes of $\mathrm{MnS}$ inclusions in $\mathrm{S} 1$ and $\mathrm{S} 2$ are $0.97 \mu \mathrm{m}$ and $1.16 \mu \mathrm{m}$, respectively, indicating that $\mathrm{MnS}$ inclusions in $\mathrm{S} 1$ are indeed smaller in

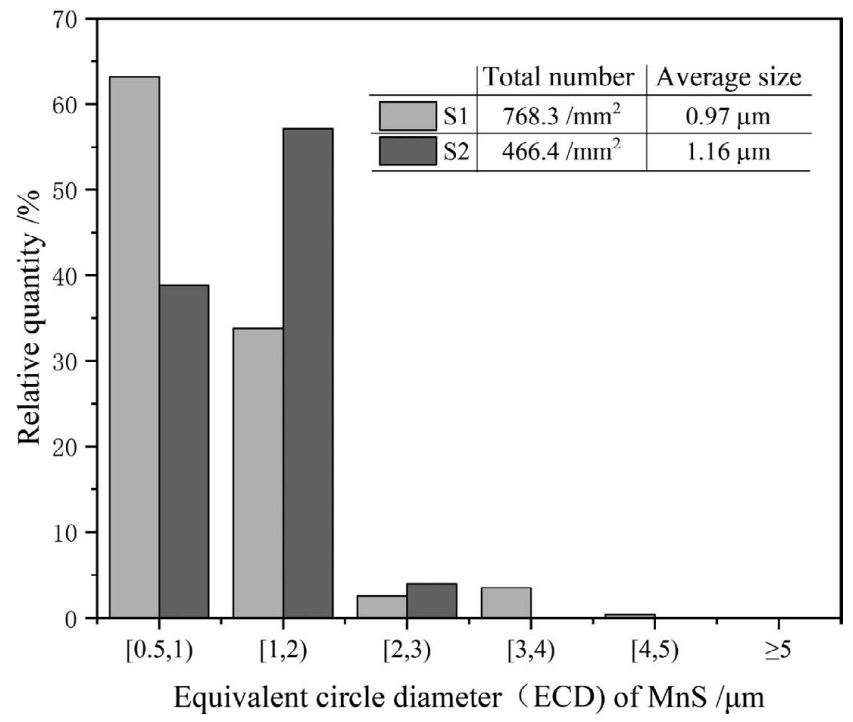

Fig. 10. Relative quantity against ECD of $\mathrm{MnS}$ in two sample steels.
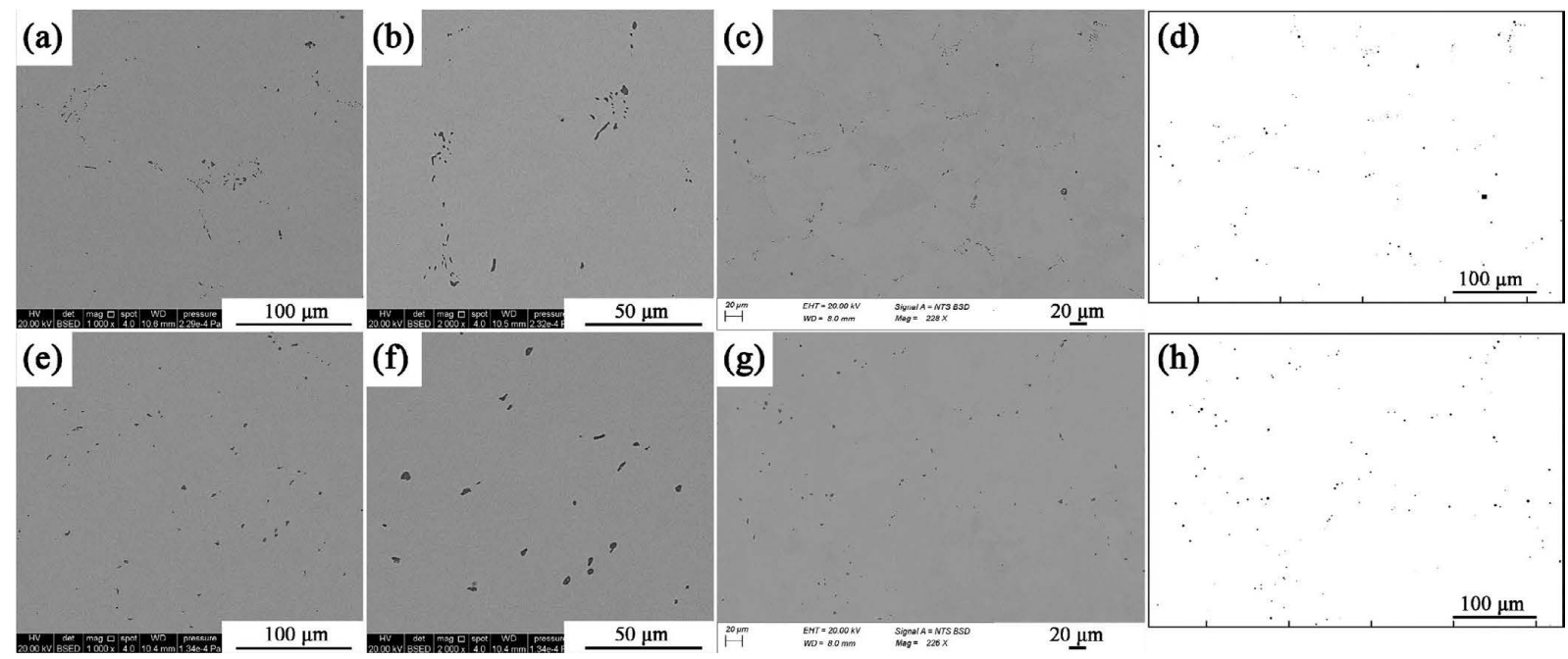

Fig. 9. SEM morphologies of MnS inclusions of two sample steels, (a-d) S1 and (e-h) S2. 


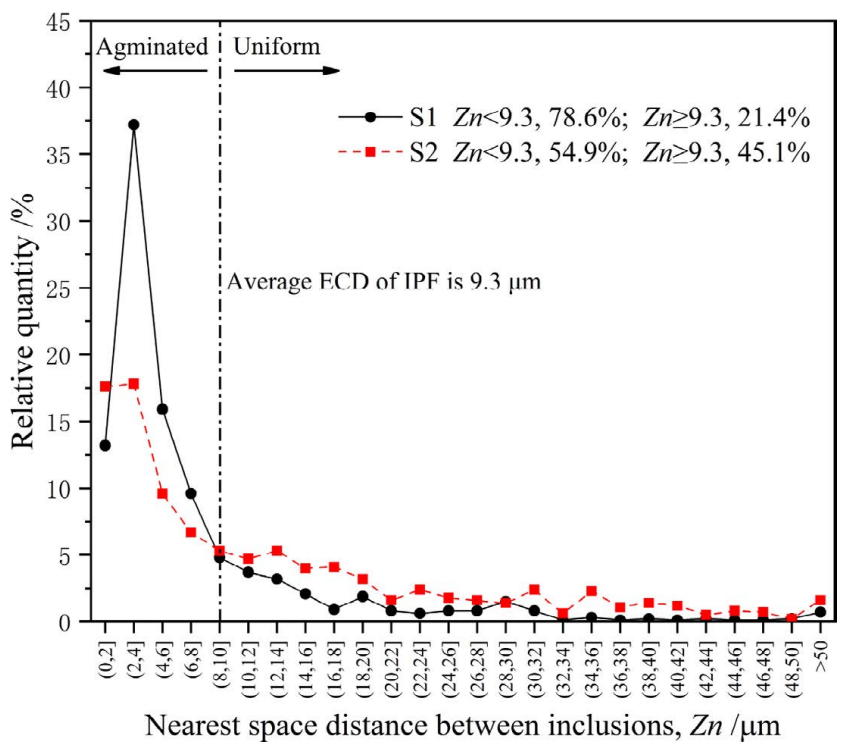

Fig. 11. Relative quantity against $Z n$ in two sample steels. (Online version in color.) (a)

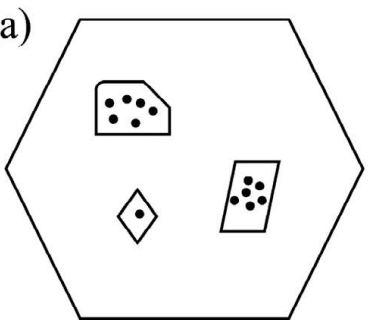

(b)

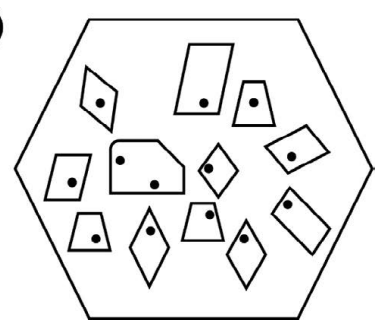

Fig. 12. Schematic diagram of effects of different MnS inclusions distributions on the IPF volume fraction (a) S1 and (b) S2.

size and larger in number than those in S2. Besides, lots of $\mathrm{MnS}$ inclusions are concentrated on size less than $2 \mu \mathrm{m}$ in both sample steels, which is appropriate for IPF promotion. ${ }^{9)}$ It is generally recognized that more $\mathrm{MnS}$ inclusions with appropriate size, more IPF microstructures would be promoted. That means characteristics of $\mathrm{MnS}$ inclusions in S1 are actually more desired for IPF formation in terms of size and amounts. However, as shown in Figs. 3 and 4 , the volume fraction of IPF in S1 is much less than that in S2. High number of inclusions is indispensable to offer adequate nucleation sites for IPF structures. But more attention should be paid on their nucleation availability. If each inclusion is adequately utilized, the inclusions content could be decreased and their detriment to other steel performance could be reduced to the minimum.

\subsubsection{Distribution}

As stated above, larger number of $\mathrm{MnS}$ inclusions does not mean higher volume fraction of IPF. The distribution characteristics of $\mathrm{MnS}$ seem more important to evaluate their nucleation effect on IPF formation. From Fig. 7, only the nearest space distance between inclusions, $Z n$ is larger than ECD of IPF, they would act as nucleation sites independently. Hence, the ECD of IPF is regarded as the critical value to determine the distribution characteristics of MnS inclusions. If $Z n$ is larger than the ECD of IPF, the inclusions are regarded as relatively uniform. Otherwise, the inclusions are regarded as agminated and they would induce IPF together, acting as only one nucleation site. (a)

(b)

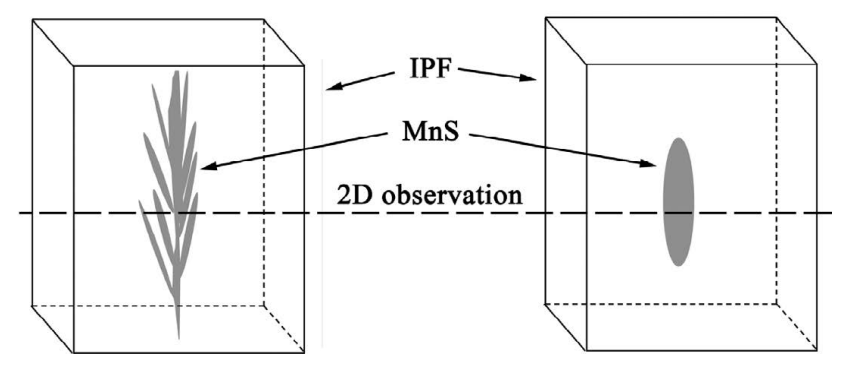

Fig. 13. Schematic diagram of IPF structures induced by $\mathrm{MnS}$ inclusions with different 3D morphologies, (a) dendritic in $\mathrm{S} 1$ and (b) spindle in S2.

$1000 \mathrm{MnS}$ inclusions in each sample steel were selected to calculate their nearest space distance with the other inclusions, the results are revealed in Fig. 11. In addition, 50 random IPF microstructures in each sample were selected to obtain their average ECD, the value is $9.3 \mu \mathrm{m}$. It should be noted that the mean ECDs of IPF in two sample steels are regarded as the same for simplicity because their value difference is minimal. In S1, the quantity of uniformly distributed $\mathrm{MnS}$ inclusions is only $21.4 \%$ while the value in $\mathrm{S} 2$ is $45.1 \%$. As stated above, these uniformly distributed $\mathrm{MnS}$ inclusions in steel are more effective on promoting IPF formation than agminated MnS inclusions. Due to the higher proportion of uniformly distributed $\mathrm{MnS}$ inclusions in $\mathrm{S} 2$, the statistical results shown in Fig. 8 indicate that 1.21 $\mathrm{MnS}$ inclusions in S2 are functionally equal to $5.48 \mathrm{MnS}$ inclusions in S1 in terms of inducing IPF microstructures.

Figure 12 is a schematic diagram of effects of different $\mathrm{MnS}$ inclusions distributions in two sample steels on the IPF volume fraction. Even the size and number of $\mathrm{MnS}$ inside of single IPF are the same, several MnS inclusions in Fig. 12(a) act as only one nucleation core due to their aggregation behavior. In Fig. 12(b), each $\mathrm{MnS}$ inclusion with space distance larger than ECD of IPF can induce one IPF individually under ideal conditions and much higher volume fraction of IPF is obtained in steel.

In the previous paper, ${ }^{17)}$ it was found the $3 \mathrm{D}$ morphologies of $\mathrm{MnS}$ inclusions were quite different in two sample steels. Most MnS inclusions in S1 are actually dendritic. As stated above, the agminated $\mathrm{MnS}$ inclusions in 2D observation are probably the secondary dendrites of the real 3D $\mathrm{MnS}$ inclusions. Figure 13 shows a schematic diagram of IPF structures induced by MnS inclusions with different 3D morphologies. The cuboids represent IPF structures and the gray graphics are $\mathrm{MnS}$ inclusions. For S1, in 2D observation, $\mathrm{MnS}$ inclusions are point or chain like, and they are smaller in size, higher in number and agminated in distribution. However, there might be only one dendritic, largesized MnS inclusion. Actually, as reported by Furuhara et al., ${ }^{12)}$ single dendritic $\mathrm{MnS}$ inclusion in S1 is more likely to induce IPF because its surface areas are larger and more $\mathrm{V}(\mathrm{C}, \mathrm{N})$ particles would generate on it. However, dendritic $\mathrm{MnS}$ inclusions are generated under much higher degree of supersaturation and they are distributed along the boundary. ${ }^{17)}$ That means their real sizes are larger, the real number are small and the distribution is agminated. As a result, lower volume fractions of IPF are obtained in S1.

The most effective method to evaluate the effects of 
dendritic MnS inclusions on IPF formation is to directly count their real number in steel matrix. However, that is quite difficult. It is more general and convenient to measure their number in 2D observation with automatic inclusions analysis systems or manually. But the results of dendritic $\mathrm{MnS}$ inclusions in 2D observation are imprecise sometimes, leading to misunderstandings. Hence, distribution characteristics of $\mathrm{MnS}$ inclusions are introduced in present study to more accurately evaluate their effects of on IPF formation. Utilizing the nearest space distances between inclusions could be effective to recognize and define these agminated $\mathrm{MnS}$ inclusions in widely used 2D observation.

\section{Conclusions}

In this paper, a quantitative characterization method of $\mathrm{MnS}$ distribution was proposed based on the data from automatic inclusions analysis software to evaluate their nucleation effects on IPF formation in NQT steels. The following conclusions could be obtained.

(1) The distribution characteristics of $\mathrm{MnS}$ inclusions would be more necessary and precise than the size and number characteristics in terms of evaluating their effects on the IPF formation.

(2) Agminated $\mathrm{MnS}$ inclusions in S1 are less effective to promote the IPF formation and lots of nucleation sites are actually wasteful because their space distances are too small to act as nucleation sites individually. Uniformly distributed $\mathrm{MnS}$ inclusions in S2 are more critical to the higher volume of IPF even their amounts are smaller. In present study, due to the higher proportion of uniformly distributed $\mathrm{MnS}$ inclusions in S2, 1.21 MnS inclusions in S2 are functionally equal to $5.48 \mathrm{MnS}$ inclusions in $\mathrm{S} 1$ in terms of inducing IPF microstructures.

(3) Due to the difference of observation method, threedimensional dendritic MnS inclusions would be revealed as several agminated small-sized ones in widely used two-dimensional observation. In order to avoid misunderstanding, the characteristics of the nearest space distances between inclusions in two-dimensional observation could be applied to recognize and define these agminated $\mathrm{MnS}$ inclusions.

\section{Acknowledgments}

The authors are grateful for financial support provided by National Natural Science Foundation of China (Grant No. 51674024 and No. 51374020). The authors also appreciate the Xining Special Steel Co., Ltd. for the technical help. The comments from the anonymous reviewer are also greatly appreciated.

\section{REFERENCES}

1) H. Kanisawa and T. Ochi: Nippon Steel Tech. Rep., 81 (2000), 22.

2) Q. Wang, G. Li and H. Dong: J. Iron Steel Res. Int., 3 (1996), 37.

3) H. Takada and Y. Koyasu: Nippon Steel Tech. Rep., 64 (1995), 7.

4) M. J. Balart, C. J. Davis and M. Strangwood: Mater. Sci. Eng. A, 284 (2000), 1 .

5) F. Zhao, M. Wu, B. Jiang, C. Zhang, J. Xie and Y. Liu: Mater. Sci. Eng. A, 731 (2018), 360.

6) A. Wang, Y. Shi and C. Chen: Mater. Sci. Technol., 33 (2017), 1942.

7) F. Ishikawa, T. Takahashi and T. Ochi: Metall. Mater. Trans. A, 25 (1994), 929.

8) J. Lu, G. Cheng, B. Tan and J. Che: ISIJ Int., 58 (2018), 921.

9) F. Zhao, N. Zhou, M. Wu, B. Jiang, J. Xie and Y. Liu: Steel Res. Int., 88 (2017), 1700133. https://doi.org/10.1002/srin.201700133

10) F. Zhao, M. Wu, B. Jiang, C. Zhang, J. Xie and Y. Liu: Mater. Charact., 140 (2018), 217.

11) T. Furuhara, T. Shinyoshi, G. Miyamoto, J. Yamaguchi, N. Sugita, N. Kimura, N. Takemura and T. Maki: ISIJ Int., 43 (2003), 2028.

12) T. Furuhara, J. Yamaguchi, N. Sugita, G. Miyamoto and T. Maki: ISIJ Int., 43 (2003), 1630.

13) G. Miyamoto, T. Shinyoshi, J. Yamaguchi, T. Furuhara, T. Maki and R. Uemori: Scr. Mater., 48 (2003), 371.

14) D. Glisic, N. Radovic, A. Koprivica, A. Fadel and D. Drobnjak: ISIJ Int., 50 (2010), 601.

15) Z. Guo, N. Kimura, S. Tagashira, T. Furuhara and T. Maki: ISIJ Int., 42 (2002), 1033.

16) S. J. Jones and H. Bhadeshia: Metall. Mater. Trans. A, 28 (1997), 2005.

17) J. Lu, G. Cheng, L. Chen, G. Xiong and L. Wang: ISIJ Int., 58 (2018), 1307.

18) T. B. Braun, J. F. Elliott and M. C. Flemings: Metall. Trans. B, 10 (1979), 171.

19) M. Wang, Y. P. Bao and L. D. Xing: ISIJ Int., 58 (2018), 886.

20) X. Wang, X. Li, Q. Li, F. Huang, H. Li and J. Yang: Steel Res. Int., 85 (2014), 155.

21) E. Storti, M. Farhani, C. G. Aneziris, C. Wöhrmeyer and C. Parr: Steel Res. Int., 88 (2017), 1700247. https://doi.org/10.1002/srin.201700247 